Hydrology and Earth System Sciences, 6(1), 1-9 (2002) C C EGS

\title{
The ethics of socio-ecohydrological catchment management: towards hydrosolidarity
}

\author{
Malin Falkenmark ${ }^{1,2}$ and Carl Folke ${ }^{2}$ \\ ${ }^{1}$ Stockholm International Water Institute \\ ${ }^{2}$ Dept of System Ecology, Stockholm University \\ Email for corresponding author: Malin.Falkenmark@siwi.org
}

\begin{abstract}
This paper attempts to clarify key biophysical issues and the problems involved in the ethics of socio-ecohydrological catchment management. The issue in managing complex systems is to live with unavoidable change while securing the capacity of the ecohydrological system of the catchment to sustain vital ecological goods and services, aquatic as well as terrestrial, on which humanity depends ultimately. Catchment management oriented to sustainability has to be based on ethical principles: human rights, international conventions, sustaining crucial ecological goods and services, and protecting ecosystem resilience, all of which have water linkages.

Many weaknesses have to be identified, assessed and mitigated to improve the tools by which the ethical issues can be addressed and solved:
\end{abstract}

- a heritage of constraining tunnel vision in both science and management;

- inadequate shortcuts made in modern scientific system analyses (e.g. science addressing sustainability issues);

- simplistic technical-fix approaches to water and ecosystems in land/water/ecosystem management;

- conventional tools for evaluation of scientific quality with its focus on "doing the thing right" rather than "doing the right thing".

The new ethics have to incorporate principles that, on a catchment basis, allow for proper attention to the hungry and poor, upstream and downstream, to descendants, and to sites and habitats that need to be protected.

Keywords: catchment, hydrosolidarity, ecosystem, water determinants, resilience, green water, blue water, sustainability science

\section{Water and ethics}

Ethics relate to social norms and moral principles. The term 'ethics', according to Webster's Dictionary (1973), is the "philosophy which treats of human character and conduct, of distinction between right and wrong, and moral duty and obligations to the community". Environmental ethics is a huge area of inquiry. Here, the focus is on the freshwater environment and its critical role in sustaining humanity.

\section{HUMANITY AND THE WATER CYCLE}

Water is a key element in the biosphere where as well as being itself a major component of living tissues and cells, it transports nutrients to and waste products away from the cells. Water has fundamental balancing functions in the natural landscape (Ripl, 1995); physically (evaporation/ condensation), chemically (crystallisation/solution) and biologically (water molecule splitting/re-assemblage through respiration). In addition, there is a whole group of largely water-dependent, yet hidden, ecosystem services (Daily, 1997) of decisive importance in the functioning of the life-support system (Lundqvist, 2000), physical, chemical as well as biological. This phase of conceptual development focuses on improved understanding and management of the interactions between society, the water cycle and ecosystem services (Fig. 1).

Conventional water concepts have focused predominantly on visible water, i.e. water as a resource to be used in society. The essential role of water in ecological processes for the generation of ecosystem services has largely been neglected, in particular in terrestrial systems (Rockström et al., 1999). The various freshwater functions that need to be accounted 


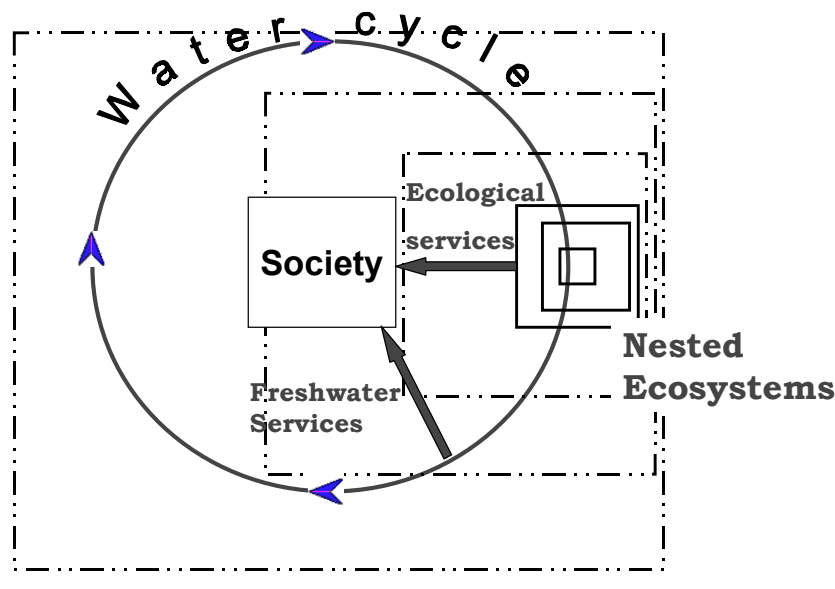

Fig. 1. A macro-scale image of key relations between society, the freshwater services and the ecological services on which its activities depend. The water cycle - the bloodstream of the biosphere - provides the water withdrawn from the water cycle for freshwater services. The ecological services originate from nested ecosystems, feeding on the same cycle.

for are summarised in Table 1. The table distinguishes between the direct use functions focused upon in the past, and those previously ignored, related to the indirect use in rainfed plant production and in other water-dependent ecological services. It also includes hidden functions involved in the generation of side effects and other consequences of human interventions in the landscape.

The deep and multiple involvement of water, in its function as the bloodstream of both the anthropogenic world and the non-human natural world, suggests that goal conflicts related to water may be numerous; there is, therefore, a whole set of ethical issues in relation to the trade-offs between them.

\section{SOCIO-NATURAL RELATIONS - DICHOTOMY OR BALANCE?}

Viewing nature and humanity as separate domains needs to be removed if society is to be directed towards sustainability. Social-natural relations are driven by different kinds of complex dynamics and with varying degrees of dependency within and between the natural and social realm. The analytical framework of complex systems (e.g. Levin, 1999) with the concept of resilience (Gunderson and Holling, 2001) is useful in this context. The framework emphasises that people need to change perspective from assuming that natural systems and freshwater dynamics are stable and controllable to a recognition of non-linear interactions and threshold effects (Scheffer et al., 2001), implying a need to learn to accept environmental change and adapt to it. The challenge is to manage freshwater to secure the capacity of the life-support system to sustain social and economic development in the face of change.

This paper is focused on the development of a biophysical conceptual framework to address ethical issues related to food production, conservation of biological diversity and social development and highlights some weaknesses in current approaches. Basically, it addresses issues related to the landscape changes needed for poverty eradication and

Table 1. Conventionally evident and hidden water functions

$\begin{array}{lll}\text { Function } & \text { Direct use } & \text { Indirect use and consequences }\end{array}$

\section{Evident Water supply}

Agricultural production

Energy production

Transport

Hidden

Watering of land
Generation of ecosystem services

Generation of side effects

- partitioning

- mobile solvent

- water cycle integrity
Household; industry

Irrigation

Hydropower

Navigation
Rainfed plant production

Terrestrial ecosystem services and resilience

Aquatic ecosystem services and resilience Waterlogging and river depletion from land use conversions

Transport of pollutants,

Cascading effects along the dynamic chain atmosphere $\Rightarrow$ terrestrial ecosystems $\Rightarrow$ groundwater, rivers, aquatic ecosystems $\Rightarrow$ coastal water ecosystems 
increased well-being, and how that can be reached without undermining the capacity of the natural life support system to humanity. It is concerned with landscape changes and the need for knowledge development and understanding of fundamental landscape functions and interactions and, in particular, of the role of freshwater in securing the capacity to sustain production of food and ecological services under conditions of change and uncertainty.

The issue is to adapt to environmental change, while securing the system's ability to sustain the production capacity on which society depends. This calls for a fundamental shift in thinking to be able, properly, to link water security, environmental security and food security. At present, they are treated as separate issues, a separation which causes unnecessary side-effects and conflicts, mismanagement of resources and societal welfare losses. The water cycle may be used as a linking mechanism.

Strong driving forces are at work; water pollution is already widespread and continues to expand with massive effects on human and ecosystem health. To manage this situation is problematic: approaches are often effect-oriented rather than cause-oriented; environmental goals must be set up with time scales appropriate to inertia in social acceptability and the highly delayed response times in natural systems. Developing understanding of the role of freshwater as the bloodstream of the biosphere and its relation to the dynamic interactions between water security, environmental security and food security is needed urgently if prosperous societal development is to be achieved within a sustainable biosphere.

\section{No human welfare without landscape changes}

\section{SOCIETAL WELFARE - BASED ON LANDSCAPE MANIPULATIONS}

The many parallel roles of freshwater in both natural and human dominated landscapes implies that the water cycle in fact links the biosphere and the anthroposphere. Nature and society may be modelled as two major subsystems with interactive linkages in which water is a key element. A fundamental task of societal leadership is to cope with environmental preconditions while satisfying humanity's needs. Water's functions in the life support system - both for health and socio-economic production, for biological production (e.g. food and timber), for ecological services (e.g. carbon sequestation), as environmental threat (floods, droughts, disease vector) and as transporter (erosion, solute transport) - makes it deeply involved in this effort. To satisfy human needs, humans have to manipulate the

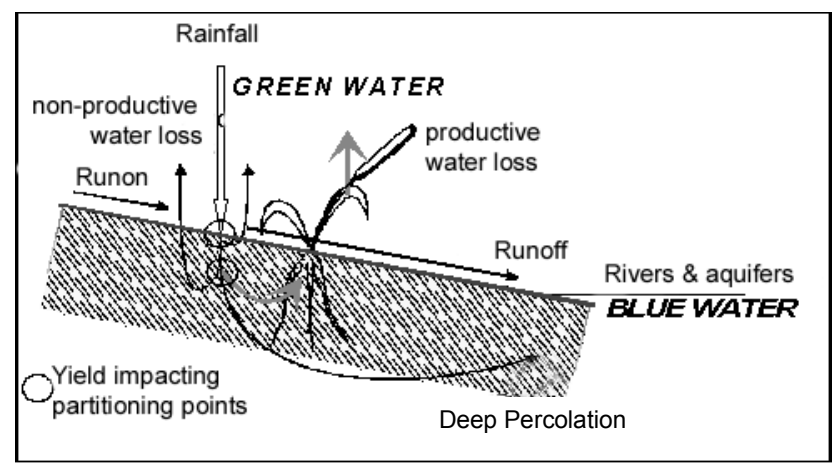

Fig. 2. At the ground surface the rainfall is partitioned between the vertical green water flow and the semihorizontal blue water flow.

landscape (clearing, draining, levelling, well-drilling, piping, channelling and cultivation). Two basic categories of manipulations may be distinguished:

(a) manipulations of water components in the landscape to satisfy direct societal water needs for water supply of households and industry and for energy production, and environmental security from floods and drought hazards;

(b) manipulations of land and vegetation for e.g. food and timber production as in monocultures of agriculture and forestry.

Both (a) and (b) give water-related effects: the former on water flows and seasonality, the latter on rainwater partitioning between vertical vapour flow (so-called green water flow) and liquid flow in rivers and aquifers (so-called blue water flow) altering river flow and seasonality, the water table, etc. (Fig. 2). Such water-related changes are equivalent to changes in key ecosystem water determinants, and are therefore reflected also in ecological changes and resilience.

\section{ENVIRONMENTAL SIDE EFFECTS FROM WATER \\ PROCESSES AT WORK IN THE LANDSCAPE}

Natural processes at work in the landscape (water movement, water dissolving capacity, water's role in sustaining ecosystems, water cycle continuity) tend to produce environmental side effects that reduce future options for social development but are partly unavoidable. This points to many ethical issues involved. One obvious example is that of adding more fertilisers to increase crop yields which may have the consequence of increased loadings of nutrients, impacting downstream aquatic ecosystems. Water's flow in the landscape defines the spatial unit through its linking of upstream and downstream activities in the catchment. 
The side effects develop in several steps and involve disturbances not only of water itself (first order effects) but also of organisms that depend on water (second order effects) and of ecosystems of which they are part (third order effects). The result is an ecological cascade with possibly distant effects by diverse links: atmospheric transport as in the case of acidification with effects on remote forests, economic effects on other nations' fishery fleets as in the case of mangrove deforestation on shrimp culture, etc.

Water's flow in the landscape makes the catchment, i.e.the area inside a water divide, a useful spatial unit in which all these different manipulations and side effects can be projected and integrated in support of an ethically-based management. The challenge is to cope with the whole gamut of different considerations needed: water needs, land use needs, terrestrial ecosystems and the goods and services that they provide, and the aquatic ecosystems and their goods and services. Management also involves the linking of upstream and downstream activities in the catchment, and the ethics involved. Reconciliation of conflicts of interest with a solidarity-based balancing of human livelihood interests is to be achieved against unavoidable environmental consequences, defined as hydrosolidarity.

\section{PHILOSOPHY OF THE PAST: ASSUME STABILITY,} MANAGE CHANGE

Past attitudes to ecosystem changes have been misleading in the sense that assumed stability has led to the belief that natural systems can be optimised and changes controlled. The stability assumption ignores surprise elements that may have accumulated over time, and that might suddenly explode into large scale calamities such as the BSE disease, the regional scale foot and mouth disease, human health hazards from hazardous chemicals now entering the mothers' milk and passing even the barrier between mother and foetus, and ecosystem deterioration reflected in decreasing populations of pollinating insects, etc.

Intergenerational equity in particular involves the need to secure both sustainable land productivity and long term resilience to sustain crucial ecological services. In ecology, disturbance is a part of system development. Strategies that aim to supress disturbance or blocking it out of the system, will not provide sustainable solutions. Such strategies, referred to as the pathology of natural resource management (Holling and Meffe, 1996), may cause an accumulation of disturbance that will hit the social-ecological system at much larger scales (Holling et al., 1998).

From local to global scales, humanity increasingly alters regimes in which organisms have evolved. Such disturbances can lead to increased variability and uncertainty about the capacity of the environment to sustain society with essential goods and services. Disturbances may be:

- physical and biological like fire, droughts, floods, pest outbreaks, diseases and human activities alter their frequency, scale and duration through e.g. large-scale land use change and climatic impacts;

- chemical and unnatural, a phenomenon unknown to the organisms;

- combined like toxins plus fire which may produce shocks to ecosystems.

\section{LEARNING TO LIVE WITH CHANGE AND MANAGE} FOR SECURING STABILITY

Past approaches to environmental ethics have had their focus on protection of certain species or certain landscape components without much attention to the changes needed to meet societal needs towards poverty and hunger eradication, and the land- and water-related changes that this will involve. van der Leeuw's (2000) study on land degradation, stressed the need to assume change and explain stability rather than assuming stability and explaining change. This switch in perspective signals the paradigm change ongoing in the social-ecological community; it is based on the realisation that change and disturbance are unavoidable - they are an integral part of the development of natural and human dominated landscapes and societal development.

\section{Water linkages in a stable life support system}

\section{ECOLOGICAL SERVICES AND THEIR WATER DETERMINANTS}

Ecological services constitute crucial components of the ecosystems to focus upon. They may be physical, chemical or biological (Lundqvist, 2000):

- physical like soil surface protection and soil infiltrability;

- chemical like oxygen production, carbon dioxide uptake and denitrification;

- biological like seed dispersal, pollination and pest insect control.

For practical reasons it is, however, impossible to work with each service separately - they are all closely linked to the ecosystem and to water's functions in that ecosystem. The challenge is to find ways to secure the capacity of the 
system as a whole to sustain its capability to support life. The catchment ecosystem depends on the involvement and mobility of water. Therefore, the protection of ecosystem services has to be linked to the management of the catchment within which there are close linkages between land, water and ecosystems.

To be able to decide on ecosystem conservation, the relevant water-related determinands have to be clarified since they indicate how ecosystems may be disturbed by water management or mismanagement. These determinants include water flow, water pathways, flow seasonality, water table and water quality/chemical characteristics, and may be affected by both direct and indirect water-related activities: by land use, by introduced pollution load, and by flow control and management measures.

Figure 3 visualises water-related causal chains between key ecosystem goods (e.g. biomass harvest) and services (e.g. the role of biodiversity in pollination), in the target end, and human activities in the landscape related to food, water and energy supply and the generation of income, in the disturbance end.

The goal is to find criteria for the protection of the capacity for sustainable production of life support within the catchment, incorporating:

- terrestrial ecosystem goods like crops, timber, grazing;
- terrestrial ecosystem services like securing soil permeability, facilitating infiltration of rainwater;

- aquatic ecosystem goods like fish;

- aquatic ecosystem services like denitrification and sedimentation.

\section{RE-ESTABLISHING DISTURBED ECOSYSTEMS}

At the same time, there is the need to secure resilience to disturbances in the sense of capacity to absorb continuous change without loss of stability. Resilience is a buffer to disturbance, and biological diversity acts as an insurance in this context. Hence, managing biodiversity is not only an ethical but also a functional issue, as biodiversity will influence ecosystem processes and redirect water flows. When loss of biodiversity reduces ecosystem resilience, it threatens the functions of that system, and hence the foundation for economic activity and human welfare (Perrings et al., 1995; Folke et al., 1996).

Since disturbance is a part of system development, there have to be components that can re-establish the ecosystem following disturbance. Biological diversity plays a role here by providing overlapping functions for restoring ecosystem capacity to generate essential services (Peterson et al., 1998). At least three components are involved here:

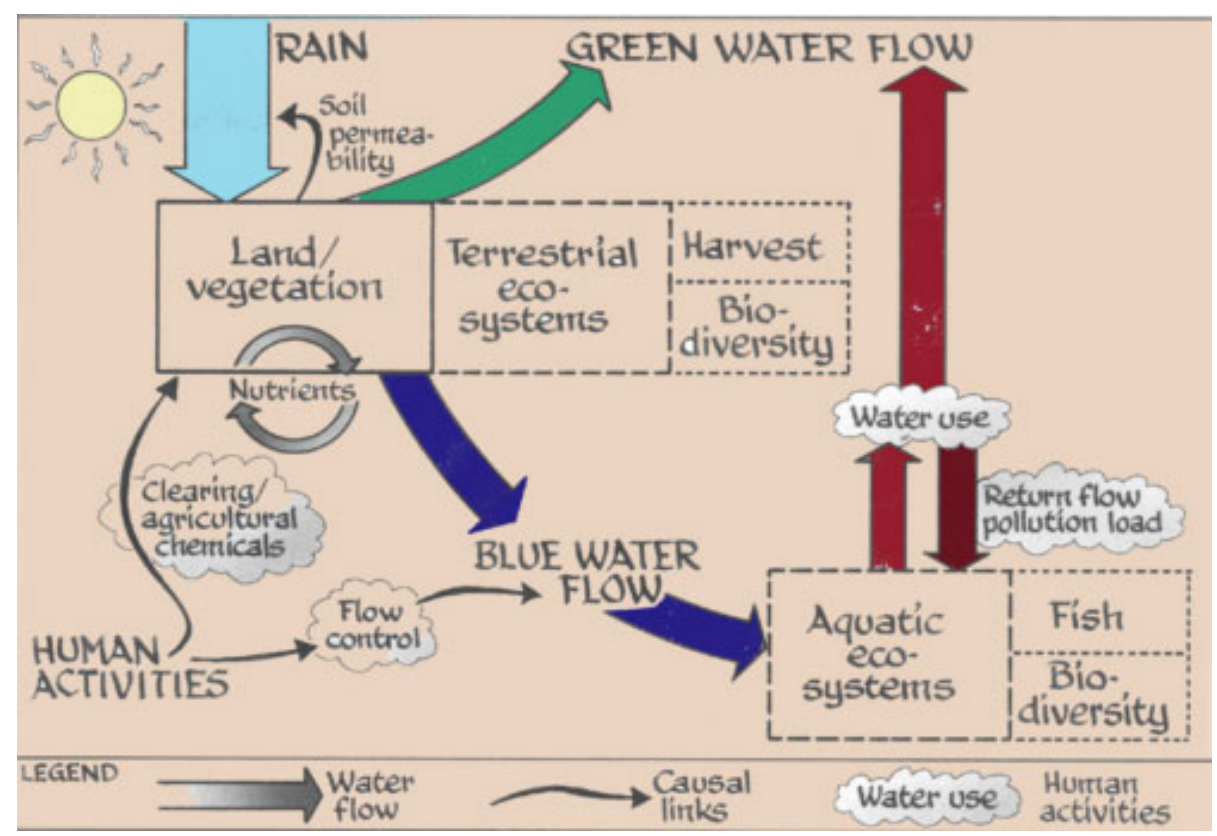

Fig. 3. Visualisation of water-related causal chains between key ecosystem goods (biomass harvests) and services (biodiversity), and human activities in the landscape related to food, water and energy sypply. Two types of landscape manipulations are important:

* on the one hand, direct manipulations of water flows and quality (flow control, water withdrawals),

* on the other, manipulation of land and vegetation, influencing soil permeability and rainwater partitioning, and consequently also water flow. After Falkenmark 2000. 
- biological legacies left in the area as cores for recovery (e.g. trees and seeds)

- mobile links like birds carrying seeds, or bats pollinating plants

- support areas for those links, like reserves or refugia, i.e. areas that were not hit by the same disturbance.

Water is fundamental for all these functions. In a forest, water in the soil allows for plant regrowth, supports the development of mycorrhiza needed for tree growth, etc. Suppression of natural forest fires locally will cause an accumulation of fuel on the forest floor as well as of tree biomass. Eventually, when a fire event occurs, it will be hot and intensive, burning deeper into the soil and affecting seed viability, micro-organisms, organic content and nutrients. A forest that can withstand a small, low-intensity fire may be affected severely by a large, hot fire that can change soil conditions, water-holding capacity, and destroy old, seedbearing trees important for the regeneration phase.

For any ecosystem function to be sustained, a minimum composition of organisms is required to develop the relations between primary producers, consumers and decomposers that mediate the flow of energy, the cycling of elements and spatial and temporal patterns of vegetation. Freshwater provides the foundation for these processes.

\section{PROTECTION OF PROCESSES, NOT SPECIES}

Organisms and their environments are connected by a complex web of interrelations and feedbacks that are nonlinear, contain lags and discontinuities, thresholds and limits (Levin, 1999). Functional robustness is based on evidence that relatively few processes, having distinct frequencies in space and time, structure ecosystems and set the rhythm of ecosystem dynamics, a pattern that seems to be particularly true for terrestrial ecosystems (Peterson et al. 1998).

However, as ecosystems are complex self-organising systems, they are characterised by multiple locally-stable equilibria, each of which corresponds to a distinct set of environmental conditions, and is controlled by a distinct set of keystone process species (Perrings et al., 1995). Therefore, keystone process species alone will not guarantee the continuation of the ecosystem in question, simply because ecosystems are faced with disturbance and surprise. It is in this context that the concept of ecosystem resilience becomes crucial in biodiversity conservation and in freshwater management. Resilience is a measure of the amount of disturbance that can be absorbed before the ecosystem moves from one stable state (e.g. a tropical forest or a coral dominated reef) to another (e.g. a tropical grassland or a macroalgae dominated reef). Moving from one configuration to another is sometimes referred to as a regime shift (Scheffer et al., in review).

\section{Ethics of ecohydrological catchment management}

\section{THE KEY CHALLENGE: SECURE DELIVERY OF CRITICAL SERVICES}

Today's simplification of the landscape implies a reduction of functional groups of biodiversity, thereby reducing the risk-spreading potential and removing the insurance for dealing with change. Options for the future and adaptive capacity are lost. Many ecosystems evolve through management to become more spatially uniform, less functionally diverse and more sensitive to disturbances that otherwise could have been absorbed. They have lost resilience. The role of freshwater for this sustenance has hitherto largely been neglected and freshwater management is seldom integrated into the management of ecosystem dynamics.

Suppression of pulse disturbance, alteration of disturbance regimes and erosion of resilience can modify essential preconditions for ecosystem redevelopment, and may trigger large-scale impact and social-ecological crisis at a later stage.

It is in this context that freshwater issues need to be coupled to issues of ecosystem management. Freshwater is required to maintain ecosystems resilient to change. Human redirection of freshwater from its natural pathways to secure human health, industrial production and food production may undermine the capacity of an ecosystem to redevelop following disturbance, thereby losing the services it generated.

To find ways and means to merge water management (allocation, upstream/downstream sharing) with land use and ecosystem management demands full awareness of the ethical dilemmas, often hidden in sectoral and narrow perspectives. The challenge is to find compromises between the obligations to respect international environmental conventions (climate change, biodiversity, droughts and desertification, etc.) and fundamental livelihood needs of the inhabitants for safe water, for food and for development, to secure protection of land productivity for future generations, to secure aquatic goods and services of downstream aquatic ecosystems, and to secure resilience of terrestrial ecosystems to natural and man-made disturbances. 


\section{IMPLICATIONS IN THE CATCHMENT PERSPECTIVE}

Implications of a socio-ecohydrological perspective in practical catchment management relate to:

- land/water development (how to do it, what to do)

- site protection considerations (where to do it)

- resilience issues (what to protect).

Basic principles are needed to guide the balancing of incompatible interests in a catchment. Freshwater management is about managing the bloodstream of the biosphere, not only for economic use within industry or households or for irrigation, but also to secure the lifesupport system that sustains societal development. Resilience processes are all deeply water dependent which means that particular phenomena in the catchment have to be integrated and sustained. Sufficient amounts of freshwater need to be allocated to terrestrial ecosystem processes and functions to secure essential ecological services. Moreover, sufficient amounts of freshwater need to be allocated to rivers, wetlands and lakes to sustain their capacity to generate essential ecological goods and services.

\section{FOCUS ON BOTH GREEN AND BLUE WATER FLOWS}

Rockström et al. (1999) showed that $87 \%$ of the water vapour flow from the continents is linked to the main global biomes in the temperate and tropical zones (Table 2).
Table 2. Green water flows

\begin{tabular}{lc}
\hline Biome & Annual green water flow $\left(\mathrm{km}^{3} \mathrm{yr}^{-1}\right)$ \\
\hline Grasslands & 15100 \\
Croplands & 6800 \\
Wetlands & 1400 \\
Woodlands and forest & 40000 \\
TOTAL & 63000 \\
\hline
\end{tabular}

When the huge water vapour flows tied to plant production are seen together with the strong driving forces active in shaping humanity's future, ecohydrological studies must address both liquid and vapour water flows in combination. This is the reason for the introduction of the concepts of blue and green water flows for the liquid and vapour flows respectively (cf. Fig. 2). In regions with high evaporative demand, land use changes may produce clear changes in the water balance currently referred to as blue-to-green redirections of water flows.

Thus, land use and terrestrial ecosystems are green water related, while the meeting of the societal needs as perceived today in freshwater management are blue water related. The basic freshwater resource is the rainfall over the catchment. This essentially turns catchment management into rainfall management with proper attention to blue/green water flow linkages (Fig. 4).



Fig. 4. Green and blue water flows as seen in the catchment perspective, where rainwater divides into a green part returning to the atmosphere as evapotranspiration, and a blue part forming runoff in rivers and aquifers. 
Freshwater management is thus not only about direct economic uses in industry and households or as a source for irrigation. Since freshwater is at the same time the bloodstream of the biosphere, it must be managed not only to secure societal development today but also to make provision for future generations.

\section{COPING STRATEGIES}

In view of this complexity, a whole set of interacting ethical issues must be treated as components of a socioecohydrological catchment management, i.e. ethics of:

- food production mode

- site selection for different activities: crop fields, reservoirs, settlements etc.

- upstream/downstream balancing of interests

- groundwater exploitation

- pollution loading

- intergenerational attention

- protection of resilience to buffer disturbance and surprise.

In this situation the past one-thing-at-a-time approach is of limited value. What is needed now is a new set of ethical principles that focuses on interactions and processes related to unavoidable changes rather than protection of a status quo. Careful attention has to be paid to the interaction between water and groups of organisms to ensure that their role in ecosystem dynamics and their functional role for human wellbeing is guarded properly. This introduces an ethical dimension to the ecohydrological landscape management process, or an ethics of process management for sustainability. It requires an improved understanding, often site-specific, of the inter-dependencies between hydrological flows and ecosystem processes and dynamics.

No successful management can be implemented without flexible institutions (norms and rules) and organisations that can monitor, interpret and shape ecohydrological change (Berkes and Folke, 1998). Principles for sustainable management of the life support system in line with the directions indicated above may be based on Ostrom's (1990) seven principles for self-regulation of human systems. Basically, these comprise the development of a proper coping capability that covers three main conditions:

- securing of social acceptance of measures that are considered necessary and limit the earlier degrees of freedom;

- arrangements for resolution of dispute between stakeholders with incompatible interests;
- attention to existing nestedness between both catchments and subcatchments on the one hand and between ecosystems on the other.

\section{Scientific renewal needed}

\section{ECOHYDROLOGICAL CONCEPTUAL DEVELOPMENT}

Here, two paradigm shifts are taking place, both within ecology (accepting change) and within hydrology (attention to vertical green water flow). Catchment management is, therefore, developing into a complex task which will demand new concepts and new research towards a sustainability science (Kinzig et al., 2000; Kates et al., 2001) where freshwater flows are addressed in a proper context. Components of socio-ecohydrological catchment management have to be considered and green- and bluewater related ethical considerations and their interrelations must be encompassed:

- green-water related: e.g. food production mode, site selection of crop fields, deforestation, afforestation, managing terrestrial ecological services, functional diversity and reslience;

- blue-water related: e.g. site selection of water sources, reservoirs, canals, pipelines, wellfields; upstream/ downstream balancing of interests; groundwater exploitation approaches; pollution loading;

- sustainability and intergenerational considerations.

The driving forces are extremely strong and constrain action on land, water and ecosystems - terrestrial as well as aquatic. Notwithstanding current concepts and mental images originating from earlier phases of environmental management, there is an urgent need for conceptual development of ecohydrology. The fundamental importance of concepts has been expressed in the following statement by the Nobel Laureate in Physics, Sir G. Thompson:

"All science depends on its concepts. These are ideas which receive names. They determine the questions one asks, and the answers one gets. They are more fundamental than the theories which are stated in terms of them."

Since water in several different roles and functions is a fundamental component of the natural processes that transform human manipulations of the landscape to satisfy human and societal needs into environmental impacts, ecosystem damages and effects on human health, these key water functions have to be entered into the over-arching environmental conceptualisation. 


\section{MANY WEAKNESSES TO OVERCOME}

The new conceptualisation has to compensate for a number of current weaknesses inherited from earlier phases of scientific development. The most basic one is the organisation of science that, basically, is inherited from the great philosopher Descartes's conceptualisation in the 17 th century, distinguishing between different aspects of the same reality (physics, chemistry, biology, etc.). This tunnel vision is mirrored also in the fragmentation of government systems.

But there are also weaknesses and shortcuts made in earlier scientific development such as the following:

- weaknesses of agroecology which tends to see water as a land attribute rather than a flow passing through the plant and vanishing to the atmosphere as a consumptive use of water that is not available for re-use downstream;

- weaknesses of the sciences addressing sustainability issues with water-blind shortcuts influenced from the time when the climate-ecosystem shortcut was introduced;

- poor linkages between ecology and hydrology originating from the same phenomenon.

\section{TOWARDS A CONSTRUCTIVE DIALOGUE}

Today's semi-blind and partial management of the landscape with poor understanding of interacting natural processes at work leads to a number of ex-post-environmental side effects which often occur as surprises. They involve ethical issues, and often conflicting goals. Many of those side effects can be avoided or reduced, and trade-offs between conflicting goals can be determined. Sustainability science and management have now to be addressed and developed so that socio-ecohydrological bridge-building through dialogue is possible. Only in that way can an intentional ex-ante-ecohydrological landscape management become possible. The complex and dynamic solar and freshwater driven life-support system of humanity needs to be viewed as an essential asset to be managed in a fashion that sustains social and economic development. It involves the development of an ethics that addresses interactions and processes for sustainability.

Beyond issues of societal demands and expectations, and ways of management of the life support system, there is the issue of ethics of scientific development. It is the duty of the scientific community to keep up, in terms of conceptual development, with understanding a world that is changing more rapidly and at larger scales than previously in human history. This approach is essential if emerging problems are to be addressed properly while taking account of human needs and rights and complying with international conventions already agreed upon. Conventional tools for evaluating scientific quality with its focus on "doing things right" have to be expanded towards "doing the right thing".

\section{References}

Berkes, F. and Folke, C. (Eds.), 1998. Linking social and ecological systems: management practices and social mechanisms for building resilience. Cambridge University Press. UK.

Daily, G., (Ed.), 1997. Nature's services: societal dependence on natural ecosystems. Island Press, Washington D.C.

Falkenmark, M., 2000. Competing freshwater and ecological services in the river basin perspective, Water Int., 25, 172-177.

Folke, C., Holling, C.S. and Perrings, C.A, 1996. Biological diversity, ecosystems, and the human scale. Ecol. Appl., 6,10181024.

Gunderson, L.H. and Holling, C.S., 2001. Panarchy; Understanding Transformations in Human and Natural Systems. Island Press, Washington, DC.

Holling, C.S. and Meffe, G.K., 1996. Command and control and the pathology of natural resource management. Cons. Biol., 10, 328-337.

Holling, C.S., Berkes, F. and Folke, C., 1998. Science, sustainability and resource management. In: Linking social and ecological systems: management practices and social mechanisms for building resilience, F. Berkes and C. Folke (Ed.), Cambridge University Press. UK. 342-362.

Kates, R.W, Clark, W.C., et al., 2001. Sustainability science. Science 292, 641-642.

Kinzig, A.P., Carpenter, S., Dove, M., Heal, G., Levin, S., Lubchenco, J., Schneider, S.H. and Starrett D., 2000. Nature and Society: An Imperative for Integrated Environmental Research. Executive Summary (http://lsweb.la.asu.edu/akinzig/ report.htm).

Levin. S., 1999. Fragile Dominion: complexity and the commons. Perseus Books. Reading, MA.

Lundqvist, J. (Ed.), 2000. New dimensions in water security. Food and Agriculture Organization of the United Nations, Land and Water Development Division (AGLW), Rome.

Ostrom, E., 1990. Governing the commons: the evolution of institutions for collective action. Cambridge University Press. UK.

Perrings, C.A., Mäler, K.G., Folke, C., Holling, C.S. and Jansson, B.O. (Eds.), 1995. Biodiversity Loss: Ecological and Economic Issues. Cambridge University Press, UK. 332 pp.

Peterson, G., Allen, C.R. and Holling, C.S., 1998. Ecological resilience, biodiversity, and scale. Ecosystems 1, 6-18.

Ripl, W., 1995. Management of water cycle and energy flow for ecosystem control: The energy-transport reaction (ETR) model. Ecol. Modelling, 78, 61-76.

Rockström, J., Gordon, L., Folke, C., Falkenmark, M. and Engvall, M., 1999. Linkages between water vapor flows, food production and terrestrial ecosystem services. Conservation Ecology, vol. 3: issue 2: article 5. [online] URL: http://www.consecol.org/ vol3/iss2/art5.

Scheffer, M., Carpenter, S., Foley, J., Folke, C. and Walker, B., 2001. Stochastic events can trigger large state shifts in ecosystems with reduced resilience. Nature, (In review).

van der Leeuw, S., 2000. Land degradation as a socionatural process, In: The way the wind blows: climate, history and human action, R.J.McIntosh., J.A.Tainter and S.K., McIntosh (Eds.), Columbia University Press, New York. 
